Sādhanā Vol. 38, Part 4, August 2013, pp. 679-686. (C) Indian Academy of Sciences

\title{
Metallurgical and mechanical characterization of mild steel-mild steel joint formed by microwave hybrid heating process
}

\author{
AMIT BANSAL ${ }^{1, *}$, APURBBA KUMAR SHARMA ${ }^{1}$ and \\ SHANTANU DAS ${ }^{2}$
}

${ }^{1}$ Mechanical and Industrial Engineering Department, Indian Institute of Technology Roorkee, Roorkee 247 667, India

${ }^{2}$ Reactor Control Division, Babha Atomic Research Centre, Mumbai 400 012, India e-mail: amit.bansal978@gmail.com

MS received 2 September 2012; revised 2 January 2013; accepted 15 April 2013

\begin{abstract}
In this paper, mild steel-mild steel (MS-MS) joints fabricated through microwave hybrid heating $(\mathrm{MHH})$ have been characterized using X-ray diffraction (XRD), scanning electron microscope (SEM), electron probe micro analyser (EPMA), Vicker's microhardness measurement and tensile strength. The XRD spectrum of the developed joints shows substitution type of solid solution form in the joint zone. The back scattered electron (BSE) images of the joint obtained by SEM show complete melting of powder particle and consequently diffusion bonding takes place between the substrate and the powder particle. The electron probe micro analysis shows diffusion of element across the joint. The Vicker's micro hardness of the joints was measured to be $420 \pm 30 \mathrm{Hv}$, which is higher than that of substrate hardness 230 $\pm 10 \mathrm{Hv}$. The tensile strength of the sample was measured by an universal testing machine and found to be $240 \mathrm{MPa}$ which is about $50 \%$ of base material strength. The SEM micrographs of the fractured sample indicate mixed modes of failure during fracture of the joint; both ductile and brittle modes of failures occurred as indicated by dimple and cleavage of the brittle faces, respectively.
\end{abstract}

Keywords. Joining; microwave; hybrid heating; diffusion bonding.

\section{Introduction}

Microwaves are electromagnetic waves with wavelengths from $1 \mathrm{~m}$ to $1 \mathrm{~mm}$ and corresponding frequencies between $300 \mathrm{MHz}$ and $300 \mathrm{GHz}$. In microwave processing, microwave energy is delivered directly to the material through molecular interaction with the electromagnetic field. Thus, there is energy conversion rather than energy transfer, which generally occurs in conventional processing of materials (Clark et al 2000; Clark \& Suttan 1996 and Thostenson \& Chou

*For correspondence 
1999). In conventional heating, slow heating rates are selected for processing of thick material to reduce steep thermal gradient resulting in reduced thermal stresses. Thus, one has to maintain balance between the product quality and processing time; otherwise, cracks may be produced inside the material because of steep thermal gradient. On the other hand, depending on the dielectric property of materials, microwave can transfer energy throughout the volume of material. So, there exists potential to reduce processing time and enhanced product quality at the same time with microwave processing of materials (Ku et al 2002; Leonelli et al 2008).

It is a known fact that not all materials can be successfully processed by microwave. The material properties that need careful consideration in microwave processing of a dielectric are complex relative permitivity $\varepsilon=\varepsilon^{\prime}-\mathrm{j} \varepsilon^{\prime \prime}$ and loss tangent $\tan \delta=\varepsilon^{\prime \prime} / \varepsilon^{\prime}$, where $\varepsilon^{\prime}$ is a measure of ability of penetration of microwave into the material, $\varepsilon^{\prime \prime}$ indicates the materials ability to store the energy and $\tan \delta=\varepsilon^{\prime \prime} / \varepsilon^{\prime}$, is an indication of ability of the material to convert absorbed energy into heat. For optimum coupling, a balanced combination of moderate $\varepsilon^{\prime}$ to permit adequate penetration and high loss $\left(\max \varepsilon^{\prime \prime}\right.$ and $\left.\tan \delta\right)$ is required. Hence, depending on the dielectric properties of material, an incident wave can be reflected, absorbed or transmitted by the material. Microwave processing of materials was mainly used for ceramics, semiconductors and polymeric materials because they are good absorbers of microwaves (Rajkumar \& Aravindan 2009; Gupta \& Wong 2007; Suttan 1989 and Metaxas \& Meredith 1983).

However metallic materials are difficult to get processed with microwave because higher reflection causes low skin depth of microwave. Roy et al (1999) found that metallic materials can be processed in powder form by making metallic powder particle size equal to skin depth. The skin depth is defined as the depth into the conductor from the surface at which the current density is $1 / e$ of its value at surface (Leonelli et al 2008). Thus, microwave processing of materials can be applied as efficiently and effectively to powdered metals as well as ceramics (Souto et al 2011; Morteza \& Omid 2010; Leonelli et al 2008 \& Sethi et al 2003). The microwaveinduced sintered products show better density, uniform microstructure, better shape retention, higher flexural strength and uniform distribution of pores (Anklekar et al 2001). Joining of metallic materials in the range of 0.1 to $0.3 \mathrm{~mm}$ has been achieved by Siores \& Rego (1995) using magnetron of power $2 \mathrm{~kW}$. The pieces were kept at a certain distance that causes arcing at the interfaces. The arcing caused localized melting of thin steel sheets and subsequently light pressure was applied to make the joint. However, joining of thick metallic materials has been reported in the form of a patent by authors (Sharma et al 2009) using MHH. The group reported the joining of similar as well as dissimilar materials (Srinath et al 2011a,b,c) with the help of microwave hybrid heating (MHH). In this study, characterization of MS-MS joints have been done, which were produced by $\mathrm{MHH}$ process. The developed joints were characterized through $\mathrm{X}$-ray diffraction (XRD), Scanning electron microscope (SEM), Electron probe micro analysis (EPMA) and Vickers's micro-hardness tester and universal testing machine.

\section{Experimental procedure}

Joining of the bulk metallic materials with the help of microwave energy is challenging, because bulk metallic materials reflect the microwave. In the present study, MHH was used for joining of MS-MS plate. A nickel-based powder of particle size $40 \mu \mathrm{m}$ was used as the interface layer for making the joint. The detailed study regarding joining of the bulk metallic material with the help of MHH has already been reported (Sharma et al 2009) in the form of a patent. The bulk MS plates of dimension $15 \times 10 \times 4 \mathrm{~mm}$ and $10 \times 10 \times 4 \mathrm{~mm}$ were placed in the butt configuration with a gap of approximately $0.4 \mathrm{~mm}$. The gap was filled with an interfacing slurry consists of 


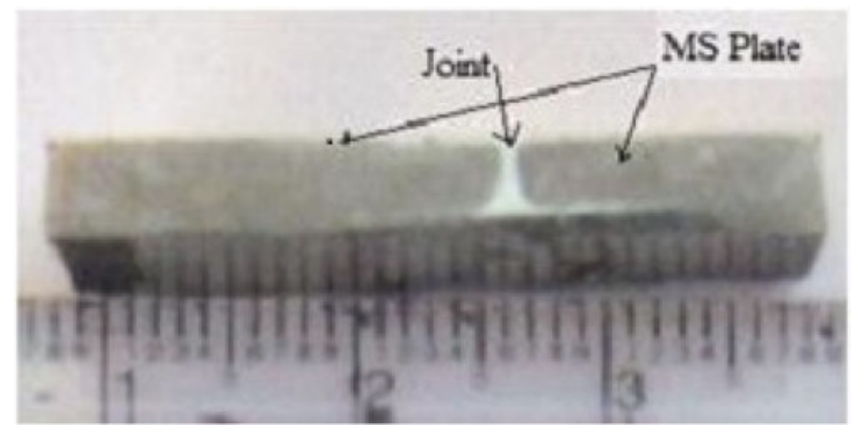

Figure 1. A view of a typical joint developed by $\mathrm{MHH}$.

Ni powder and an epoxy resin (Bisphenol-A, Blumer 1450XX). The bulk material reflects the microwave at room temperature. In order to avoid the problem of reflection, the bulk metallic pieces were covered with insulator mask so that they are not directly exposed to microwave. The joint zone was covered with a susceptible material so as to enable microwave coupling initially. The configuration was exposed to microwave radiation for $600 \mathrm{~s}$ at $2.45 \mathrm{GHz}$ and $900 \mathrm{~W}$. A view of a joint developed with the help of $\mathrm{MHH}$ is shown in figure 1.

\subsection{Characterization of the joints}

Developed joints were cut perpendicular to the original interface by $200 \mu \mathrm{m}$ diamond cutter followed by mechanical polishing and etching. The joints were characterized by XRD, SEM (FEI, Quanta 200 FEG-SEM Czech Republic), EPMA (Make: JEOL, Model: JXA- 8600 M), Vicker's micro hardness tester (Mini load, Leitz, Germany). Tensile strength of the joints was evaluated by an UTM as per ASTM standard (ASTM Designation: E8/E8 M - 09, 2009).

\section{Results and discussion}

The results of various characterizations are discussed with suitable illustrations in the following sections.

\subsection{X-ray diffraction results}

Typical XRD spectra of the starting Ni powder used as an interface layer and that of the developed joints are shown in figure $2 a$ and $b$, respectively. It is clear from figure $2 a$ that initial powder mainly contains $\mathrm{Ni}$ as dominating element along with some amount of $\mathrm{Cr}$. However, from figure $2 \mathrm{~b}$, it is clear that during microwave irradiation, the melting of powder takes place along with melting of a thin layer of substrate interfaces. This facilitates diffusion of element across the interface and formation of substitution type of solid solution between $\mathrm{Fe}, \mathrm{Ni}$ and $\mathrm{Cr}$.

\subsection{SEM observation}

The Back scattered electron (BSE) image of the typical joint developed through MHH is shown in figure $3 \mathrm{a}$ and $\mathrm{b}$, respectively. The BSE image shows the complete melting of the powder 

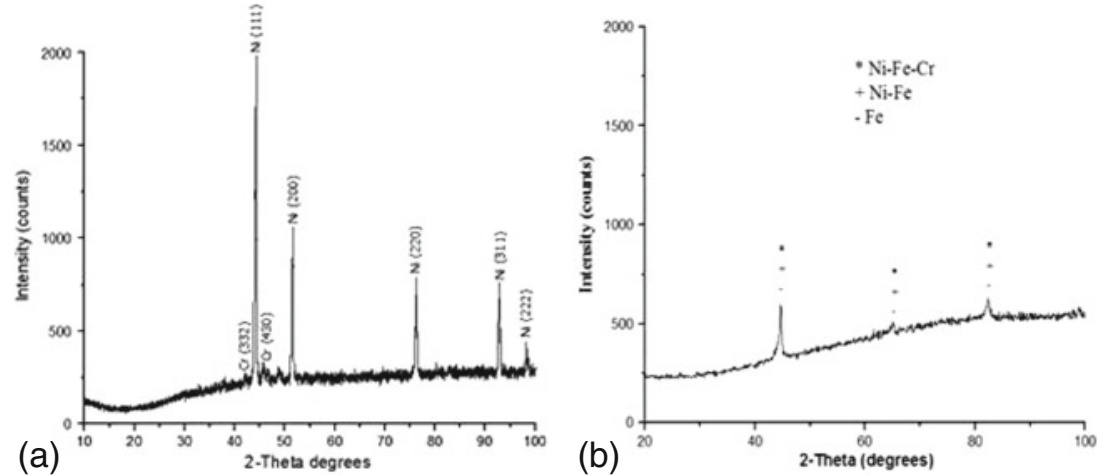

Figure 2. XRD spectrum of (a) the Ni powder, (b) the joint developed by MHH.

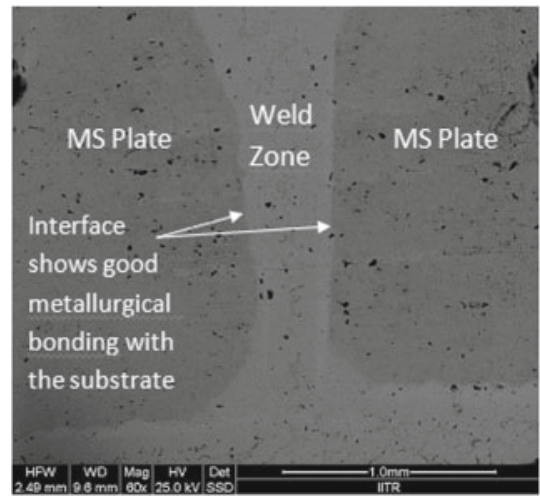

(a)

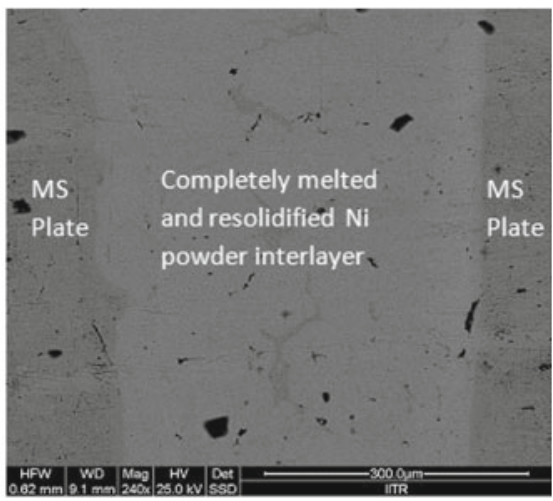

(b)

Figure 3. BSE images show typical (a) microstructure of the joint, (b) magnified view of the joint.

particle and metallurgical bonding with the substrate. The joint is free from any pores and cracks. A dense and homogenous structure is formed at the joint. The observed homogeneity of the joint is due to volumetric heating of the material. Since microwave can penetrate inside the material and transfer energy directly to the material, heat can be generated through the volume of material resulting in volumetric heating. Charcoal powder was used as a susceptor for initial coupling of microwave. Charcoal powder after absorbing microwave gets heated to high temperature and consequently, it transfers heat to Ni-based powder layer through alumina plate used as a separator in this experiment by conventional mode of heat transfer. At elevated temperature, the powder starts absorbing microwave and consequently its temperature rises which is sufficient for its melting. The molten powder wets the interfacing surfaces and consequently melting of interfacing surfaces will take place. But melting of interfacing surfaces are limited to a thin layer only due to low skin depth of bulk metallic materials (Gupta \& Wong 2007).

\subsection{Elemental study}

Compositional profile of the joint was analysed through EPMA. The typical results are presented in figure 4. The compositional profile was carried out in a BSE image at the location 


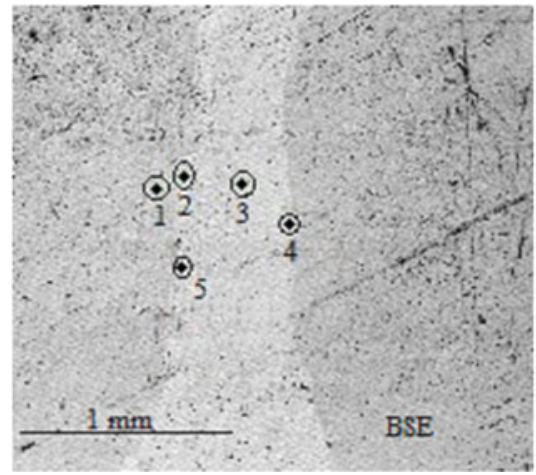

(a)

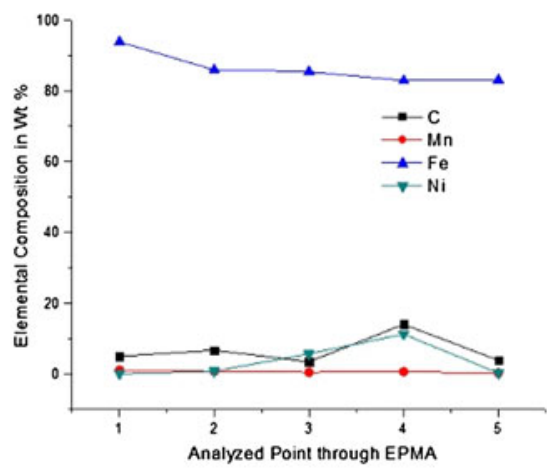

(b)

Figure 4. Compositional profile of the joint. (a) Locations for element analysis, (b) distribution of the major elements.

specified in the figure 4a. The corresponding weight percentages have been plotted in figure $4 \mathrm{~b}$. Figure $4 \mathrm{~b}$ confirms that the joints contain $\mathrm{Fe}$ and $\mathrm{Mn}$. Although the interfacing powder layer consists mainly of $\mathrm{Ni}$ and $\mathrm{Cr}$. Thus, the presence of these elements in the solidified Ni powder layer indicates that iron and manganese got diffused from the mild steel substrate into the interface zone during $\mathrm{MHH}$ by way of convection current of the melt pool which helps in formation of the metallurgical bonds.

\subsection{Observation on microhardness}

Microhardness of the MS-MS joint was measured on the joint, on the interface and on the substrate of the base metal using a load of $50 \mathrm{~g}$ for $20 \mathrm{~s}$. Typical morphology of indentation is shown in a circle shown in figure 5a. From figure 5a, it is clear that the indentations are smaller in dimensions made on the weld zone, but larger in dimensions made on the base metal. This clearly indicates that the weld zone has a higher hardness as compared to base metal. Micro

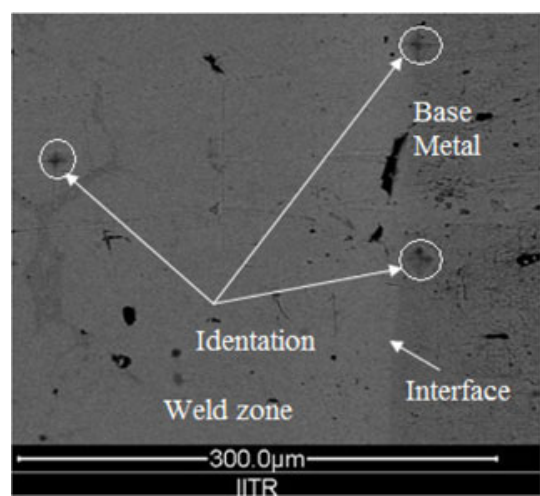

(a)

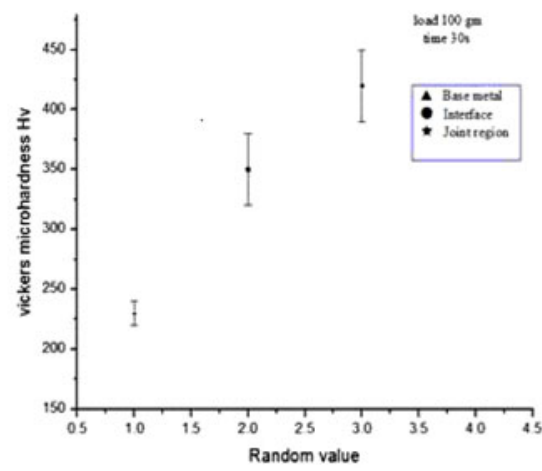

(b)

Figure 5. (a) Vicker's microhardness indentation shown by white circle, (b) Vickers microhardness value at various zones. 
hardness on the substrate and on the interface was measured to be $230 \pm 10 \mathrm{Hv}$ and $350 \pm 30 \mathrm{Hv}$, respectively, whereas it was measured to be maximum on the joint, about $420 \pm 30 \mathrm{Hv}$ as shown in figure $5 \mathrm{~b}$. The high hardness at the joint may be attributed to the presence of hard carbides that are likely to form at the joint. This was also indicated by the identification of $\mathrm{Si}, \mathrm{Mn}$ and other carbide-forming elements along with carbon in the joint zone (interfacing layer) as observed in figure 4. Carbide formation in the joint zone during microwave joining of SS-SS has also been reported by Srinath et al (2011c).

\subsection{Observation on tensile strength test}

In order to determine the tensile properties of the fabricated joints, the joints were subjected to standard tensile test. The joints were made according to ASTM standard having a gauge length of $18 \mathrm{~mm}$ and thickness of $3.5 \mathrm{~mm}$. A uniform strain rate of $8.3 \times 10^{-3} \mathrm{~mm} / \mathrm{s}$ was applied. The joint shows an ultimate tensile strength of $250 \mathrm{MPa}$ which is about $50 \%$ of base metal strength and elongation of $6 \%$. However, relatively higher joint strength and elongation of the microwave irradiated joints while joining MS-SS and SS-SS steel have been reported by Srinath et al $(2011 \mathrm{~b}, \mathrm{c})$. The authors have reported $346.6 \mathrm{MPa}$ joint strength and $13.58 \%$ elongation while joining MS-SS.

The fractured pieces of the tensile specimens were further studied through SEM. The locations for taking the SEM images are shown in figure 6. Figure $6 \mathrm{~b}$ and $\mathrm{c}$ shows the fractured surfaces of the microwave-induced MS-MS joint. It is clear from the figure that mixed mode of failure occurred during failure of the joint. Both ductile as well as brittle mode of failures were observed during the fracture of the joint as evidenced by sharp separation (brittle failure) and the plastic deformation (lip formation) in the ductile mode failure as shown in figure $6 \mathrm{~b}$ and $\mathrm{c}$. The ductile failure is due to the presence of relatively soft matrix consisting of solidified Ni powder and brittle failure is due to the presence of carbide phases present in the material. When a load is applied, the matrix is subjected to plastic deformation, but these carbide precipitates do not cope up with the matrix deformation. When a critical value of load is reached, cleavage of

(a)
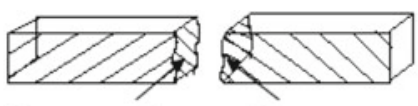

Fracture counter surface
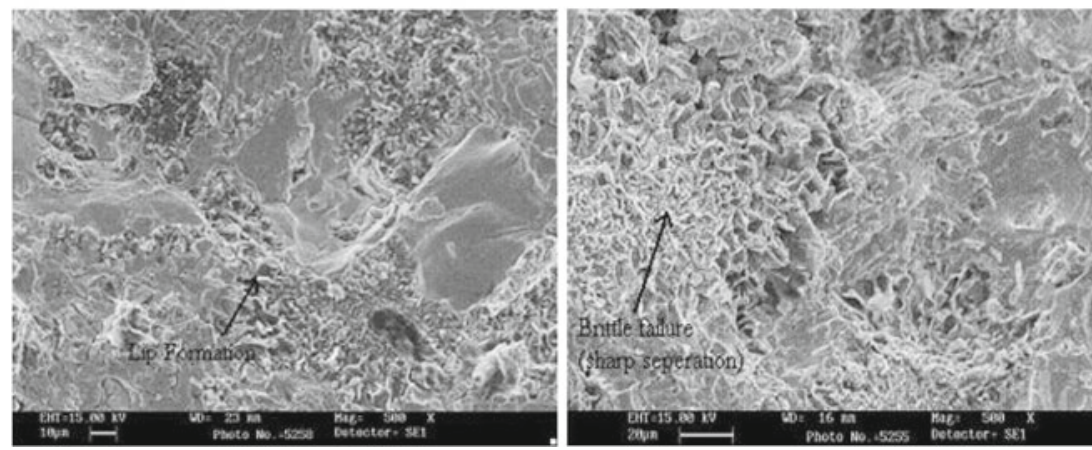

(b)

(c)

Figure 6. (a) Location for taking SEM image of fracture surface is shown by arrow, (b) micrograph of fractured surface, $(\mathbf{c})$ micrograph of fractured counter surface. 
brittle phases (carbide particle) takes place. Thus, both ductile and brittle failure take place in the fracture of the joint. The ductile failure is due to the presence of relatively soft matrix consisting of solidified Ni powder and brittle failure is due to the presence of carbide phases present in the material. When a load is applied, the matrix is subjected to plastic deformation, but these carbide precipitates do not cope up with the matrix deformation. When a critical value of load is reached, cleavage of brittle phases (carbide particle) takes place. Thus, both ductile and brittle failure take place in the fracture of the joint.

\section{Conclusion}

In this paper, characterization of MS-MS joints have been carried out by various characterization techniques. The conclusions of the study are summarized as follows.

- Substitutional type of solid solutions are formed in the interfacing zone during joint formation through MHH.

- Good metallurgical bonding between the powder and substrate material is obtained. A dense and homogenous joint is obtained without any pores and cracks.

- Fe and Si are uniformly distributed in the interfacing zone and carbon is also present in the interfacing zone.

- Microhardness of the joint is more at the joint due to formaiton of various carbide elements like chromium carbide.

- The joints exhibit tensile strength approximately $50 \%$ of the base material strength.

- The fractography study shows mixed mode of failure showing both brittle and ductile failures. Brittle failure is due to various carbide phases present in the joint and ductile failure is due to relatively soft $\mathrm{Ni}$ matrix.

\section{Acknowledgement}

The authors would like to thank the Board of Research in Nuclear Sciences (BRNS), Mumbai, Government of India for financial assistance through Research Project Grant No. 2010/36/60BRNS/2048.

\section{References}

Anklekar R M, Agrawal D K and Roy R 2001 Microwave sintering and mechanical properties of P/M steel. Powder Metall. 44(4): 355-362

ASTM Designation: E8/E8M - 092009 Standard test methods for tensile testing of metallic materials, American Association State Hgihway and Transport Officials Standard AASHTO No: T 68, An American National Standard. 1-3

Clark D E and Suttan W H 1996 Microwave processing of materials, Annu. Rev. Mater. Sci. 26: 299-331

Clark D E, Folz C E and West J K 2000 Processing materials with microwave energy. Mater. Sci. Eng. A 287: $153-158$

Gupta M and Wong W L E 2007 Microwaves and metals, Singapore: John Wiley and Sons (Asia) Pte Ltd. 45

Ku H S, Siores E and Taube A 2002 Productivity improvement through the use of industrial microwave technologies. Comput. Ind. Eng. 42: 281-290

Leonelli C, Veronesi P, Denti L, Gatto A and Iuliano L 2008 Microwave assisted sintering of green metal parts. J. Mater. Process. Technol. 205: 489-496 
Metaxas A C and Meredith R J 1983 Industrial microwave heating. UK: Peter Peregrinus Ltd. 99-100

Morteza O and Omid M 2010 Microwave versus conventional sintering: A review of fundamentals, advantages and applications. J. Alloys Compd. 494: 175-189

Rajkumar K and Aravindan S 2009 Microwave sintering of copper-graphite composites. J. Mater. Process. Technol. 209: 5601-5605

Roy R, Agrawal D, Cheng J and Gedevanishvili S 1999 Full sintering of powdered metals parts in a microwave field. Nature. 399: 668-70

Sethi G, Upadhyaya A and Agrawal D 2003 Microwave and conventional sintering of pre-mixed and prealloyed Cu-12 Sn bronze. Sci. Sinter. 35(2): 49-65

Sharma A K, Srinath M S and Kumar Pradeep 2009 Microwave joining of metallic materials. Indian patent application no. 1994/Del/2009

Siores E and Rego D 1995 Microwave applications in material joining. J. Mater. Process. Technol. 48: 619-625

Souto P M, Menezes R R and Kiminami R H G A 2011 Effect of $\mathrm{Y}_{2} \mathrm{O}_{3}$ additive on conventional and microwave sintering of mullite. Ceram. Int. 37: 241-248

Srinath M S, Sharma A K and Kumar Pradeep 2011a A new approach to joining of bulk copper using microwave energy. Mater. Des. 32(5): 2685-2694

Srinath M S, Sharma A K and Kumar Pradeep 2011b Investigation on microstructural and mechanical properties of microwave processed dissimilar joints. J. Manufact. Process. 13: 141-146

Srinath M S, Sharma A K and Kumar Pradeep 2011c A novel route for joining of austenite stainless steel (SS-316) using microwave energy. Proc Institution Mech. E Part B J. Eng. Manufact. 225: 1083-1091

Suttan W H 1989 Microwave processing of ceramic materials. Am. Ceram. Soc. Bull. 168: 376-386

Thostenson E T and Chou T W 1999 Microwave processing: fundamentals and applications. Composites: Part A 30 (9): 1055-1071 